\title{
Supportive Hepatocyte Transplantation after Partial Hepatectomy Enhances Liver Regeneration in a Preclinical Pig Model
}

\author{
Felix Oldhafer $^{\mathrm{a}} \quad$ Eva-Maria Wittauer $^{\mathrm{a}} \quad$ Oliver Beetz $^{\mathrm{a}} \quad$ Clara A. Weigle $^{\mathrm{a}}$ \\ Lion Sieg $^{b}$ Hendrik Eismann $^{\mathrm{b}}$ Peter Braubach ${ }^{c, d}$ Michael Bock ${ }^{\mathrm{e}}$ \\ Danny Jonigk $^{c, d}$ Kai Johanning ${ }^{b}$ Florian Wolfgang Rudolf Vondran ${ }^{a, f}$ \\ ${ }^{a}$ ReMediES, Department of General, Visceral and Transplant Surgery, Hannover Medical School, Hannover, \\ Germany; ${ }^{b}$ Department of Anaesthesiology and Intensive Care Medicine, Hannover Medical School, Hannover, \\ Germany; ${ }^{C}$ Institute for Pathology, Hannover Medical School, Hannover, Germany; ${ }^{\mathrm{d}}$ Member of the German Center \\ for Lung Research (DZL), Marburg, Germany; ${ }^{~}$ Department of Gastroenterology, Hepatology and Endocrinology,

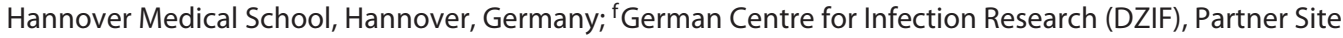 \\ Hannover-Braunschweig, Hannover, Germany
}

\section{Keywords}

Hepatocyte transplantation · Liver regeneration · Liver resection

\begin{abstract}
Background: Hepatocyte transplantation ( $\mathrm{HTx}$ ) is regarded as a potential treatment modality for various liver diseases including acute liver failure. We developed a preclinical pig model to evaluate if $\mathrm{HTx}$ could safely support recovery from liver function impairment after partial hepatectomy. Methods: Pigs underwent partial hepatectomy with reduction of the liver volume by $50 \%$ to induce a transient but significant impairment of liver function. Thereafter, 2 protocols for $\mathrm{HTx}$ were evaluated and compared to a control group receiving liver resection only (group $1, n=5$ ). Portal pressure-controlled HTx was performed either immediately after surgery (group $2, n=6$ ) or 3 days postoperatively (group $3, n=5$ ). In all cases, liver regeneration was monitored by conventional laboratory tests and the novel noninvasive maximum liver function capacity (LiMAx) test with a follow-up of 4 weeks. Results: Partial hepatectomy significantly impaired liver
\end{abstract}

karger@karger.com www.karger.com/esr

Karger $\stackrel{\text { ' }}{=}$
(C) 2021 The Author(s)

Published by S. Karger AG, Basel

This is an Open Access article licensed under the Creative Commons Attribution-NonCommercial-4.0 International License (CC BY-NC) (http://www.karger.com/Services/OpenAccessLicense), applicable to the online version of the article only. Usage and distribution for commercial purposes requires written permission. function according to conventional liver function tests as well as LiMAx in all groups. A mean of $4.10 \pm 1.1 \times 10^{8}$ and $3.82 \pm 0.7 \times 10^{8}$ hepatocytes were transplanted in groups 2 and 3 , respectively. All animals remained stable with respect to vital parameters during and after HTx. The animals in group 2 showed enhanced liver regeneration as observed by mean postoperative LiMAx values (621.5 vs. $331.3 \mu \mathrm{g} / \mathrm{kg} / \mathrm{h}$ on postoperative day $7 ; p<0.001$ ) whereas HTx in group 3 led to a significant increase in mean liver-specific coagulation factor VII (112.2 vs. $54.0 \%$ on postoperative day 7; $p=$ 0.003 ) compared to controls (group 1), respectively. In both experimental groups, thrombotic material was observed in the portal veins and pulmonary arteries on histology, despite the absence of clinical symptoms. Conclusion: HTx can be performed safely and effectively immediately after a partial (50\%) hepatectomy as well as 3 days postoperatively, with comparable results regarding the enhancement of liver function and regeneration.

(c) 2021 The Author(s)

Published by S. Karger AG, Basel

F.O. and E.-M.W. contributed equally to this work.
Correspondence to:

Florian Wolfgang Rudolf Vondran, vondran.florian@mh-hannover.de 
Fig. 1. Anatomic situs and histology. a Anatomic situs after partial hepatectomy. b Presentation of the exteriorized 7-french portal venous catheter (arrow) for supportive hepatocyte transplantation. c, d Representative histology following partial hepatectomy and supportive HTx showing frequently observed thrombotic events. HE. Organized thrombi were detected in liver veins (c) and pulmonary arteries (d).
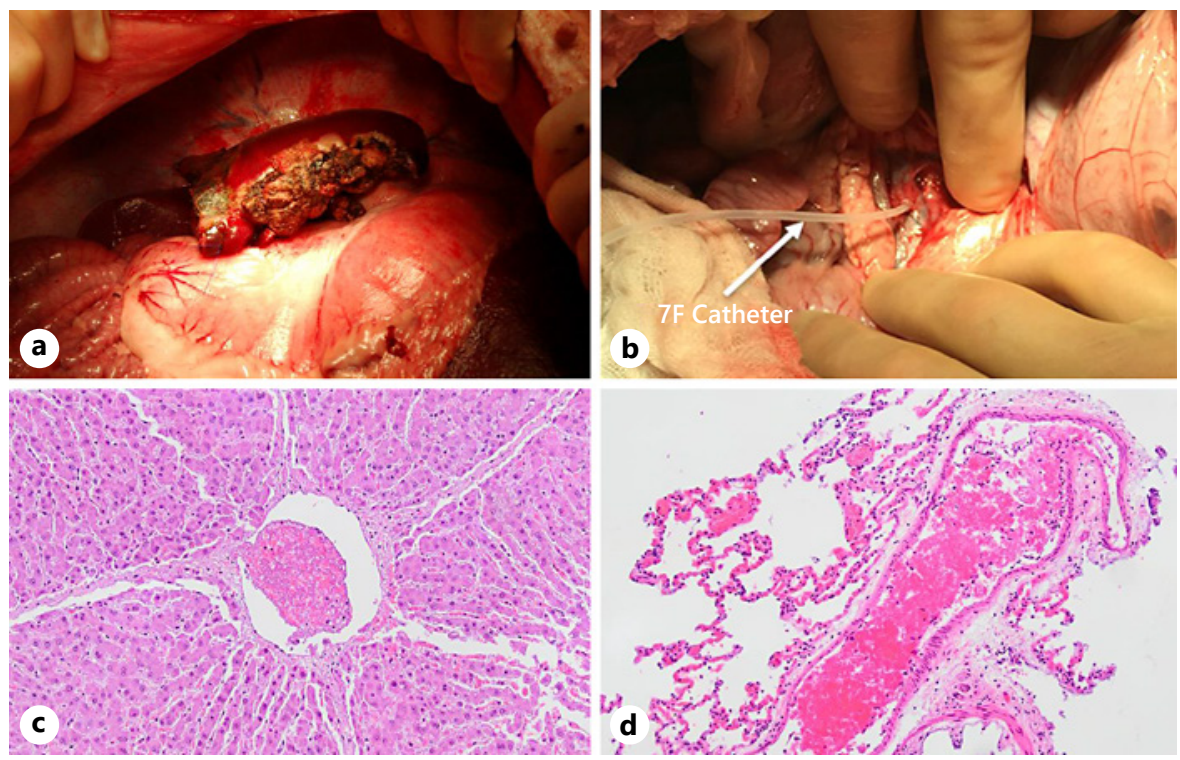

\section{Introduction}

Hepatocyte transplantation ( $\mathrm{HTx}$ ) is a promising therapeutic approach for various liver diseases and, in selected cases, a potential alternative to orthotopic liver transplantation (OLT) [1] which is currently considered the gold standard for end-stage liver disease. Experience with clinical applications of HTx in humans is, however, still limited. The first transplantation of autologous hepatocytes was performed in 10 patients with liver cirrhosis in Japan in 1992 [2]. Since then, $>100$ patients have been treated with HTx worldwide [3]. Various indications for HTx have been described in the past, most of them similar to those for OLT. In most clinical cases the correction of congenital metabolic liver disorders has been the indication for HTx, but the potential of HTx in patients with acute liver failure was recently evaluated [4]. Although HTx has resulted in partial correction of liver diseases, its long-term efficacy is still hampered by low viability or numbers of donor hepatocytes as well as the insufficient engraftment and acceptance of cellular allografts, despite the use of modern immunosuppression [5]. Exactly which patients would benefit most from HTx remains a matter of debate. Previously, we developed a porcine model of liver regeneration after partial hepatectomy with a future liver remnant (FLR) of 50\% [6]. The aim of this study was to analyze if supportive HTx is safe and effectively enhances liver regeneration in the setting of partial hepatectomy.

Supportive HTx after Partial Hepatectomy

\section{Materials and Methods}

\section{Partial Hepatectomy}

Healthy female LEWE minipigs with a mean age of $456.0 \pm 23.6$ days and a body weight (BW) of $46.0 \pm 3.0 \mathrm{~kg}$ were used as subjects/ recipients. In all animals, partial hepatectomy was performed as a subtotal resection on 3 of 5 liver lobes, aiming for a FLR of about $50 \%$ (Fig. 1a) as previously described [6]. In brief, liver resection was performed with vascular clamps and monopolar dissection, or with a linear stapler, depending on the anatomical conditions of the respective liver lobes. Hemostasis was achieved by electrocoagulation and sutures. The Pringle maneuver was not used in any of the liver resections, to avoid warm ischemia of the FLR. All animals were equipped with a central venous catheter (left internal jugular vein) and an externalized portal venous catheter (via the superior mesenteric vein; Fig. 1b) as described previously [7]. The liver weight of the animals was estimated as follows: $491.86 \times \mathrm{LN}$ (BW in kg) - 1,249.8 [6]. The FLR was calculated as follows: 100 - (resected liver weight in $\mathrm{kg} \times 100 /$ estimated liver weight in $\mathrm{kg}$ ). The FLR-to-BW ratio was calculated as follows: FLR/BW.

\section{Hepatocyte Isolation}

Hepatocyte isolation was performed from whole organs (a mean liver weight of $595.5 \pm 37.0 \mathrm{~g}$ ) by applying a 5-step collagenase perfusion protocol on the day of cell transplantation. The protocol was adapted from previous studies in humans $[8,9]$. Healthy male LEWE minipigs $(n=11)$ with a mean age of $391.6 \pm 26.1$ days and a BW of $44.2 \pm 3.0 \mathrm{~kg}$ served as hepatocyte donors. The procurement of the liver was performed as described in humans [10]. Afterwards, the organ was flushed with approximately 2,000 $\mathrm{mL}$ of washing buffer. The washing buffer was then washed out of the liver with approximately 2,000 mL of Hank's Balanced Salt Solution. In the next step, $500 \mathrm{mg}$ of collagenase (collagenase P) in 1,000 $\mathrm{mL}$ of digestion buffer with recirculation was started, allowing for tissue digestion of about $15 \mathrm{~min}$. Collagenase was then removed by perfusion with $500 \mathrm{~mL}$ of washing buffer, followed by $250 \mathrm{~mL}$ of 


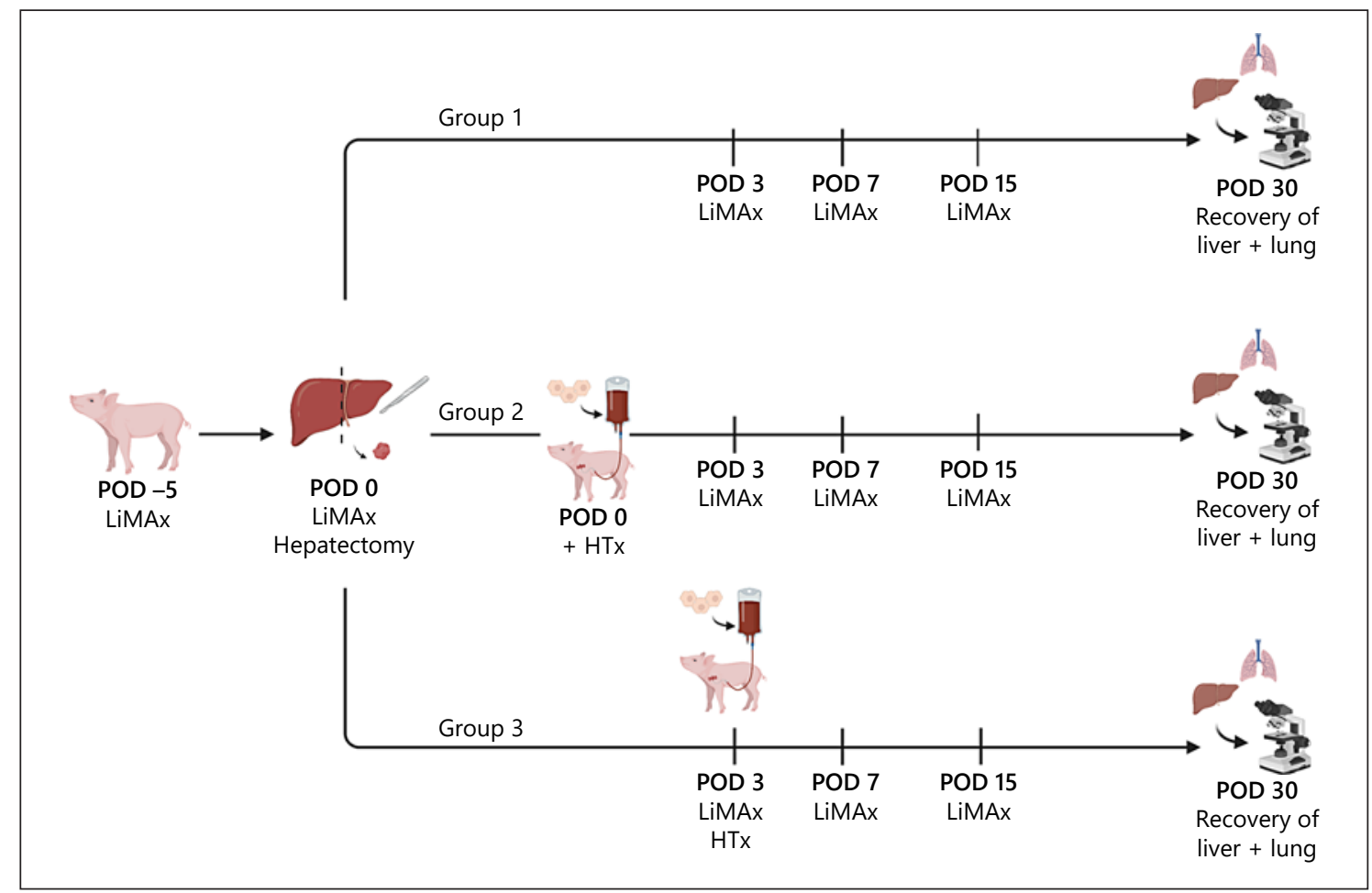

Fig. 2. Study design and time points of interventions. LiMAx test was performed on day -5 , and POD $0,3,7$, and 15. Animals received hepatocyte transplantation on POD 0 and 3 for groups 2 and 3, respectively. After 30 days, animals were euthanized, and liver and lung tissue recovered for histological work-up. LiMAx, liver maximum capacity test; HTx, hepatocyte transplantation; POD, postoperative day.

washing buffer without EGTA but with albumin 5\%. Afterwards, the organ was sliced and the hepatocyte suspension was filtered through a gauze-lined funnel and centrifuged at $50 \mathrm{~g}$. To prevent clumping of hepatocytes, an incubation of $25 \mathrm{mg}$ DNase in $250 \mathrm{~mL}$ special DNase buffer was performed. Thereafter, the hepatocytes were again filtered through a gauze-lined funnel and washed with PBS solution and centrifuged. Mean viability of the cells was $85.0 \pm$ $2.1 \%$ as determined by Trypan blue exclusion test. Hepatocytes were suspended in PBS, transferred into a transfusion bag, and stored on ice until transplantation. The detailed composition of the abovementioned reagents is summarized in the online supplementary material (see www.karger.com/doi/10.1159/000516690).

\section{Hepatocyte Transplantation}

In all cases, male-to-female HTx was performed using freshly isolated porcine hepatocytes suspended in PBS at $2.8 \pm 0.5 \times 10^{6}$ viable cells $/ \mathrm{mL}$. Cells were transplanted via the portal venous catheter either immediately after liver resection (group 2) or on the third postoperative day (POD, group 3). The study design including the experimental protocol is displayed in Figure 2. Infusion was started at $1 \mathrm{~mL} / \mathrm{h}$ with subsequent increase of the flow rate (mean of $87.0 \pm 11.7 \mathrm{~mL} / \mathrm{h}$ ) according to the portal venous pressure. During HTx, hemodynamic parameters including the central venous and portal venous pressures were monitored continuously. Transplantation was temporarily stopped if the portal venous pressure exceeded $25 \mathrm{~mm} \mathrm{Hg}$. After HTx, animals received immunosup- pression including tacrolimus with trough whole blood levels of 5-10 $\mu \mathrm{g} / \mathrm{L}$ and prednisolone (POD 0: $500 \mathrm{mg}$, POD 1: 125, POD 2-14: $20 \mathrm{mg}$, POD 14-30: $15 \mathrm{mg}$ ).

\section{Postoperative Care}

Animals were visited at least twice daily and additionally according to medical needs. Blood samples were taken daily in the first week. In addition to testing the conventional laboratory values, the maximum liver function capacity (LiMAx) test was used to monitor liver function prior to hepatectomy, directly after liver resection, and on POD 3, 7, and 15, respectively. During the first 3-5 POD, all pigs received adjusted fluid and volume therapy with isotonic electrolyte solution, depending on respective results of blood gas analyses, until values normalized. Additionally, $1 \mathrm{~g}$ tranexamic acid (Carinopharm $\mathrm{GmbH}$, Elze, Germany) was intravenously administered over $16 \mathrm{~h}$ after the beginning of the partial hepatectomy. Animals were followed-up until planned euthanasia on POD 30 (bolus injection of a lethal dose of pentobarbital sodium). Starting on POD 3, 100 I.E. heparin were continuously administered daily via the portal venous catheter. Clinical and laboratory results were recorded as described below.

\section{Maximum Liver Function Capacity}

The maximum liver function capacity (LiMAx test) is based on the quantification of ${ }^{13} \mathrm{C}$-methacetin metabolism by the liver-specific cytochrome P450 1A2 system [11]. As previously described 
Table 1. Details of the partial hepatectomies performed

\begin{tabular}{lcccc}
\hline & Group 1 $(n=5)$ & Group 2 $(n=6)$ & Group 3 $(n=5)$ & $p$ value* \\
\hline Liver resectate, g & $285 \pm 10$ & $277 \pm 18$ & $279 \pm 17$ & $0.931 ; 0.214 ; 0.891$ \\
FLR, \% & $54.5 \pm 1.1$ & $54.6 \pm 1.9$ & $46.2 \pm 3.3$ & $0.931 ; 0.056 ; 0.126$ \\
FLR/BW & $1.2 \pm 0.1$ & $1.3 \pm 0.1$ & $1.3 \pm 0.1$ & $0.792 ; 0.222 ; 0.931$ \\
CVP pre Rx, mm Hg & $12.8 \pm 1.2$ & $12.0 \pm 1.0$ & $10.4 \pm 0.9$ & $0.708 ; 0.119 ; 0.253$ \\
CVP post Rx, mm Hg & $12.2 \pm 0.8$ & $11.3 \pm 1.8$ & $10.8 \pm 0.9$ & $0.810 ; 0.238 ; 0.498$ \\
PVP pre Rx, mm Hg & $15.6 \pm 0.9$ & $13.7 \pm 0.3$ & $14.6 \pm 1.1$ & $0.088 ; 0.722 ; 0.494$ \\
PVP post Rx, mm Hg & $17.4 \pm 1.6$ & $15.2 \pm 0.5$ & $16.4 \pm 0.6$ & $0.507 ; 0.968 ; 0.171$ \\
\hline
\end{tabular}

* Group 1 vs. group 2; group 1 vs. group 3; group 2 vs. group 3.

Table 2. Details of the hepatocyte transplantations performed

\begin{tabular}{llccc}
\hline & Group 1 $(n=5)$ & Group 2 $(n=6)$ & Group 3 $(n=5)$ & $p$ value* \\
\hline Hepatocytes, $\times 10^{8}$ & n.a. & $4.10 \pm 1.1$ & $3.82 \pm 0.7$ & 0.755 \\
Hepatocytes $/ / \mathrm{kg} \mathrm{BW})$ & n.a. & $9.9 \pm 2.8$ & $10.2 \pm 1.8$ & 0.931 \\
Volume, mL & n.a. & $136.7 \pm 16.0$ & $134.6 \pm 13.4$ & 0.877 \\
Duration of HTx, min & n.a. & $113.0 \pm 29.4$ & $118.4 \pm 13.9$ & 0.662 \\
CVP pre HTx, mm Hg & n.a. & $11.5 \pm 0.8$ & $12.0 \pm 3.6$ & 0.675 \\
CVP post HTx, mm Hg & n.a. & $12.8 \pm 2.2$ & $12.4 \pm 3.7$ & 0.999 \\
PVP pre HTx, mm Hg & n.a. & $17.8 \pm 1.8$ & $18.6 \pm 0.9$ & 0.887 \\
PVP peak, mm Hg & n.a. & $24.8 \pm 1.3$ & $26.8 \pm 1.2$ & 0.507 \\
PVP post HTx, mm Hg & n.a. & $24.3 \pm 1.5$ & $25.6 \pm 0.7$ & 0.472 \\
Median number of interruptions & n.a. & 2 & 5 & 0.513 \\
Liver growth, \% & $122 \pm 47$ & $108 \pm 35$ & $183 \pm 25$ & $0.792 ; 0.556 ; 0.038$
\end{tabular}

Bold type denotes statistical significance $(p<0.05){ }^{*}$ For comparison of group 2 and group 3 (except for the variable liver growth) with comparison of group 1 and group 2, group 1 and group 3, and group 2 and group 3 , respectively. n.a., not applicable.

[6], a cone-shaped mouthpiece was placed on the animal's snout to measure the ${ }^{13} \mathrm{CO}_{2} /{ }^{12} \mathrm{CO}_{2}$ ratio within the exhaled air. The LiMAx measurements were performed in each animal, after fasting for at least $8 \mathrm{~h}$, at the following time points: 5 days before the operation (day -5), intraoperatively directly after liver resection, and on POD 3, 7, and 15, respectively. In order to perform LiMAx tests, pigs were sedated with an intramuscular injection of tiletamine, zolazepam, and atropine, and repeated intravenous application of propofol, respectively. After defining the baseline ${ }^{13} \mathrm{CO}_{2} /{ }^{12} \mathrm{CO}_{2}$ ratio during native expiration, $2 \mathrm{mg} / \mathrm{kg}{ }^{13} \mathrm{C}$-methacetin solution (Humedics $\mathrm{GmbH}$ ) were intravenously administered and the ${ }^{13} \mathrm{CO}_{2} /{ }^{12} \mathrm{CO}_{2}$ ratio dynamic was recorded over a time period of at least $30 \mathrm{~min}$. The LiMAx values were calculated with the previously described formula [11].

\section{Histology}

Tissue samples for histology were taken from multiple localizations of the liver and lung. The tissue was fixed overnight in buffered $4 \%$ formaldehyde, and subsequently embedded in paraffin according to standard histopathological protocols. For histologic evaluation, $4-\mu \mathrm{m}$-thick sections were cut and stained with hematoxylin and eosin.

Supportive HTx after Partial Hepatectomy
Statistical Analysis

Statistical analyses were performed using GraphPad Prism v8.4.00 (GraphPad Software, Inc., La Jolla, CA, USA). The Student $t$ test and paired $t$ test, the Mann-Whitney $\mathrm{U}$ test and analysis of variance (ANOVA) test as well as the Tukey post hoc test were applied as appropriate. Differences were regarded statistically significant when $p<0.05$. Results are expressed as mean \pm SEM, unless indicated otherwise.

\section{Results}

\section{Partial Hepatectomy}

All animals successfully underwent partial hepatectomy in terms of left trisegmentectomy, with comparable volumes of liver parenchyma being resected: $285 \pm 10 \mathrm{~g}$ in the control group (group 1), and $277 \pm 18 \mathrm{~g}(p=0.931)$ and $279 \pm 17 \mathrm{~g}(p=0.241)$ in the HTx groups (compared to group 1 , respectively). This resulted in comparable 


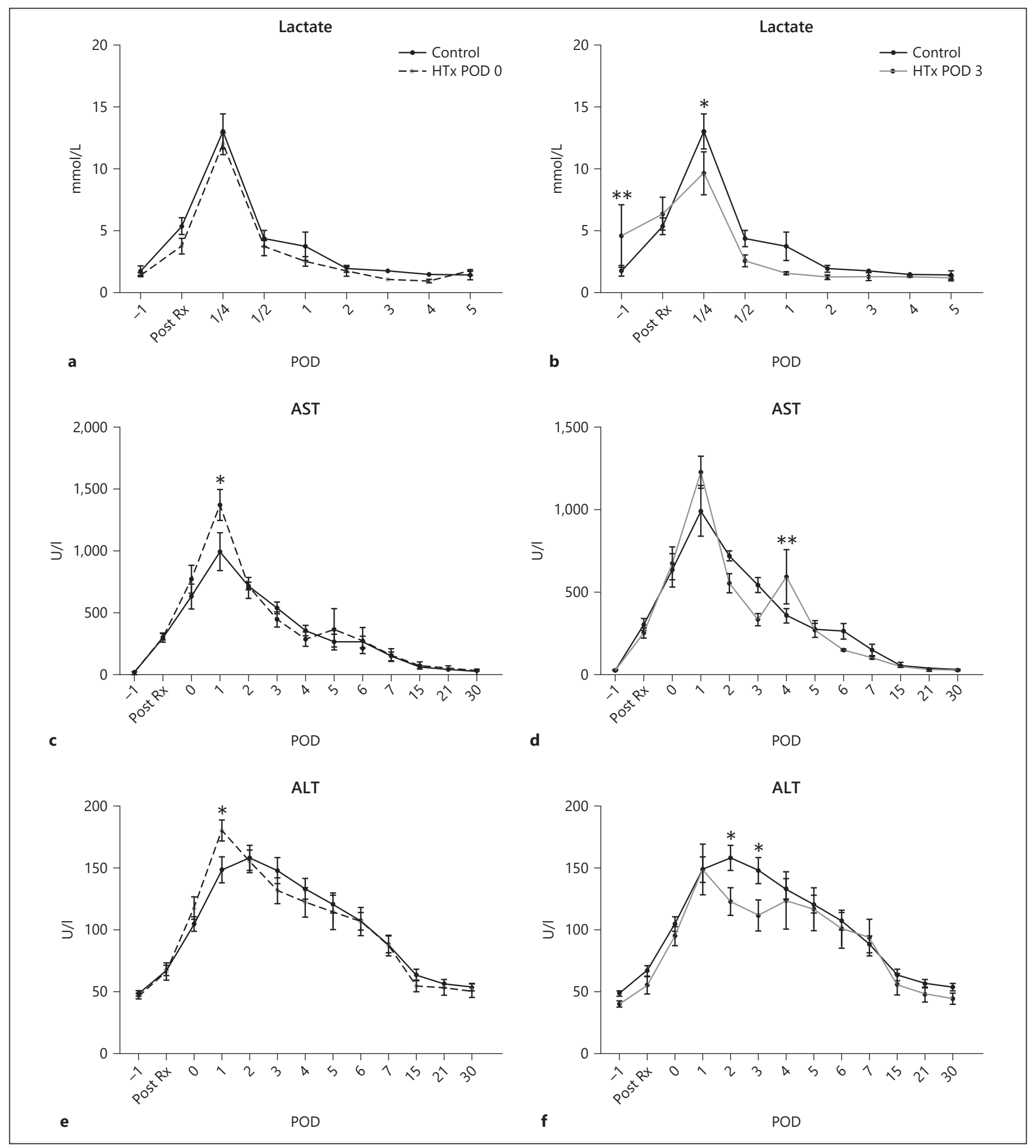

Fig. 3. Laboratory values after partial hepatectomy with/without supportive HTx. a, b The course of lactate during the first 5 days. c-f The courses of AST and ALT during the whole experiment. Comparison of control group 1 (black line) with HTx groups 2 (dotted line) and 3 (grey line), respectively. Post Rx, after liver resection; POD, postoperative day; HTx, hepatocyte transplantation. ${ }^{*} p<0.05$ versus the control group; ${ }^{* *} p<0.05$ versus group 1 (controls) and group 2 (HTx). 


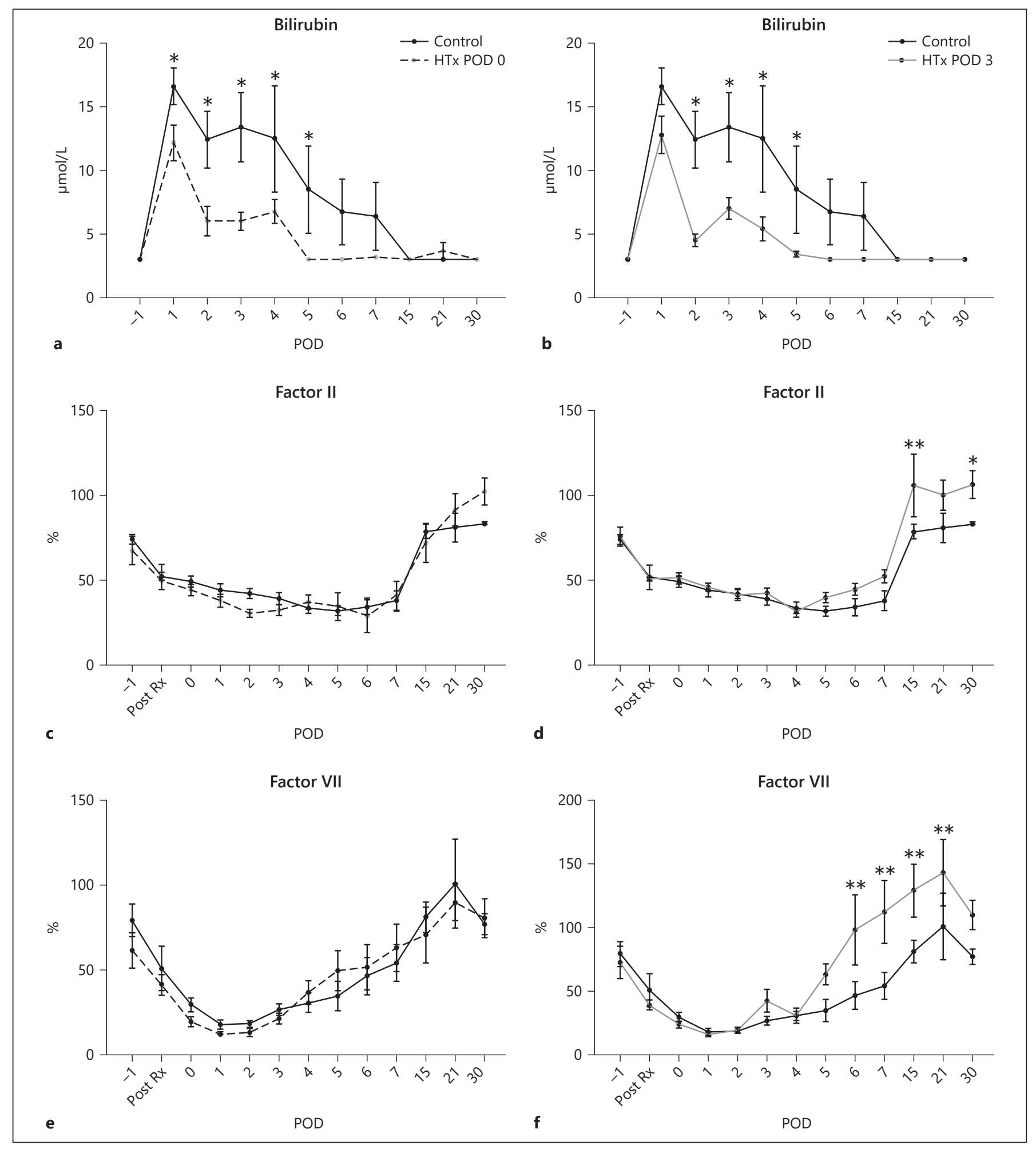

Fig. 4. Course of laboratory values after partial hepatectomy with/without supportive HTx. a-f The courses of bilirubin, factor II, and factor VII during the whole experiment. Comparison of control group 1 (black line) with HTx groups 2 (dotted line) and 3 (grey line), respectively. Post Rx, after liver resection; POD, postoperative day; HTx, hepatocyte transplantation; ${ }^{*} p<0.05$ versus the control group 1 ; ${ }^{* *} p<0.05$ versus group 1 (controls) and group 2 (HTx). 
mean FLRs of $54.5 \%, 54.6 \%(p=0.931)$, and $46.2 \%(p=$ $0.056)$ as well as FLR/BW of $1.2 \%, 1.3 \%(p=0.792)$, and $1.3 \%(p=0.222)$ for groups 1,2 , and 3 , respectively. There were no significant differences concerning the pre- and postoperative central and portal venous pressures in the different groups. Detailed information regarding the liver resections for all groups is summarized in Table 1.

\section{Hepatocyte Transplantation}

HTx following partial hepatectomy was successfully conducted in all cases $(n=11)$, without any serious adverse events such as hemodynamic instability or acute thrombosis of the portal venous catheter. A mean number of $4.10 \pm 1.1 \times 10^{8}$ and $3.82 \pm 0.7 \times 10^{8}$ hepatocytes were transplanted in groups 2 and 3 , respectively $(p=$ $0.755)$. The average time of transplantation did not differ significantly between the 2 treatment groups (113.0 \pm 29.4 vs. $118.4 \pm 13.9 \mathrm{~min} ; p=0.662$ ).

In contrast to the central venous pressure which remained stable throughout the entire intervention, the portal venous pressure significantly increased during HTx in all animals $(18.2 \pm 1.0$ vs. $24.8 \pm 0.8 \mathrm{~mm} \mathrm{Hg}$ prior to and at the end of transplantation, respectively; $p<$ $0.001)$. In the course of the experiment, the portal venous pressure, by trend, was slightly higher in animals transplanted on POD 3 (24.8 \pm 1.3 vs. $26.8 \pm 1.2 \mathrm{~mm} \mathrm{Hg}, p=$ 0.507). Accordingly, interruption of HTx due to an increase of portal venous pressure $>25 \mathrm{~mm} \mathrm{Hg}$ was also more frequently observed in group 3 than in group 2 . Detailed information regarding the HTx in all groups are summarized in Table 2.

\section{Laboratory Results and Clinical Course after HTx}

All animals showed significant impairment of liver function following partial hepatectomy, according to conventional laboratory parameters as well as the LiMAx test. Lactate peaked at $6 \mathrm{~h}$ after liver resection in all groups, but returned to baseline within $48 \mathrm{~h}$. Levels of AST and ALT peaked on POD 1 and were lower in group 1 (995.8 $\pm 153.5 \mathrm{U} / \mathrm{L}$ and $148.5 \pm 10.5)$ than in group $2(1,374.2 \pm$ $125.6 \mathrm{U} / \mathrm{L} ; p=0.006$ and $180.0 \pm 8.5 ; p=0.030$, respectively) and group $3(1,230.4 \pm 97.48 \mathrm{U} / \mathrm{L} ; p=0.065$ and $148.8 \pm 20.4 ; p=0.999$, respectively). Thereafter, in groups 1 and 2, AST and ALT levels decreased continuously to baseline until the end of the experiment. Only the animals in group 3 showed a secondary increase in AST after HTx on POD 3. Levels of bilirubin also increased shortly after partial hepatectomy and were significantly higher in group 1 than in groups 2 and 3 on POD $2(p=0.0001$ and $p<0.001)$, POD $3(p<0.001$ and $p=0.002)$, POD $4(p=$

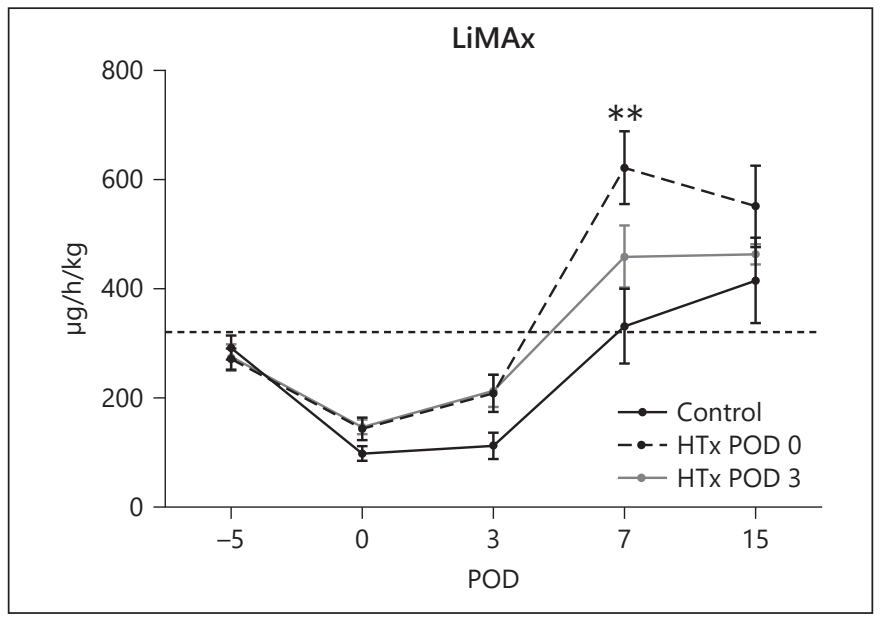

Fig. 5. Course of LiMAx after partial hepatectomy with/without HTx. LiMAx values on POD 0, 3, 7, and 15 as well as prior to liver resection (day -5), respectively. Comparison of control group 1 (black line), HTx group 2 (dotted black line) and HTx group 3 (grey line). The thin dotted black line marks the cut-off value for regular liver function $(315 \mu \mathrm{g} / \mathrm{kg} / \mathrm{h})$ in humans. LiMAx, liver maximum capacity test; HTx, hepatocyte transplantation; POD, postoperative day. ${ }^{* *} p<0.05$ versus the control group and group 3 (HTx).

0.014 and $p=0.001)$, and POD $5(p=0.035$ and $p=0.024)$, respectively. Of note, recipients in group 3 showed significant lower values of lactate, ALT, and bilirubin compared to the control group before undergoing HTx.

In the early postoperative course, levels of coagulation factor II did not differ between controls and animals receiving HTx. However, in the further course, the level continuously increased in group 3; static factor II levels were observed for control animals reaching statistical significance on POD 15 and $30(p=0.009$ and $p=0.030)$. Animals in group 2 also showed a higher factor II level on POD 21 and 30, but without these reaching statistical significance. Of note, on POD 15, the levels of factor II also differed significantly between the 2 HTx groups $(p<$ 0.001). Furthermore, a significantly higher level of factor VII was observed in group 3 than in groups 1 and 2 on POD $6(p=0.009$ and $p=0.020)$, POD $7(p=0.003$ and $p=0.009)$, POD $15(p=0.016$ and $p=0.001)$, and POD $21(p=0.040$ and 0.004$)$, respectively. The animals in group 2 showed no significant differences concerning the levels of factor VII when compared to the controls. All conventional laboratory data above are displayed in Figures 3 and 4.

The LiMAx test demonstrated significant loss of maximum liver function capacity immediately after partial hepatectomy in all animals (Fig. 5). In the further course 
of the experiment, liver function capacity was seen to recover significantly faster in group 2 , with respect to the LiMAx values on POD 7, than in groups 1 and 3 (621.5 \pm $66.2 \mu \mathrm{g} / \mathrm{kg} / \mathrm{h}$ vs. $331.3 \pm 69.0 \mu \mathrm{g} / \mathrm{kg} / \mathrm{h}$ vs. $458.8 \pm 57.4 \mu \mathrm{g} /$ $\mathrm{kg} / \mathrm{h} ; p<0.001$ and $p=0.041$ ). All animals recovered well from partial hepatectomy and supportive HTx in groups 2 and 3. None of the animals showed severe complications or clinical symptoms of a thromboembolic event after HTx. The clinical course was thus comparable to that of the control group.

\section{Histology of the Liver and the Lung}

Following partial hepatectomy with/without HTx, there was a mild hypertrophy of the liver with expanded liver lobules and increased cellular hypertrophy compared to baseline samples. After euthanasia, the weight of the explanted livers had increased by $122 \pm 47 \%, 108 \pm$ $35 \%$ and $183 \pm 25 \%$, respectively, compared to the calculated liver weight after liver resection (Table 2).

Following supportive HTx, in some cases, organized thrombotic material could be observed within large portal vein branches (Fig. 1c). Other than that, no relevant inflammation or fibrosis could be detected. In lung samples, thrombotic obliteration of the medium and small pulmonary arteries (compatible with recent thromboembolic events) accompanied by mild pulmonary edema was likewise frequently observed following supportive HTx (Fig. 1d). No thrombotic alterations were observed in control animals (group 1).

\section{Discussion}

HTx has the potential to become a reliable therapeutic option for acute and chronic liver failure and to overcome the limitations of liver transplantation in times of organ donor shortage in selected patients. However, the optimal preconditioning, the timing of transplantation, the source of hepatocytes and the best indications for HTx have still to be clarified.

There are small case series about HTx for acute liver failure which resulted in clinical improvement $[4,12]$. Furthermore, some of the studies on rodents showed the successful use of HTx to promote liver regeneration and even avoid the development of potentially life-threatening posthepatectomy liver failure [13-15]. However, no literature is available regarding HTx for liver function improvement after partial hepatectomy in humans or preclinical pig models. Nevertheless, liver resection without significant functional impairment itself has been dis- cussed as a preconditioning regimen to induce a favorable environment for hepatocyte engraftment prior to HTx [16-18]. In this context, endothelial cell damage as well as the release of proinflammatory cytokines might play a key role [18]. Accordingly, the most effective/successful time point for HTx might depend on the release of mitogenic stimuli such as hepatocyte growth factor (HGF), interleukin 6 , and tumor necrosis factor $a$. The postoperative courses of coagulation factor II and factor VII, displayed in this study, indicated the best recovery of liver function following delayed HTx (POD 3), possibly explained by a more pronounced accumulation of mitogenic stimuli. Nonetheless, HTx performed immediately after partial hepatectomy also significantly improved liver function as determined by the noninvasive LiMAx test displaying liver-specific CYP-1A2 metabolism. Of note, the LiMAx values as well as the levels of factor II and VII at the end of our study period exceeded the preoperative values. Ideally, this reflects the positive effects of HTx in combination with the regeneration of a healthy liver, especially since this observation was most evident in groups 2 and 3 . With regard to factor II and factor VII, HTx has been performed in patients with factor VII deficiency and decreased the need for factor VII substitution [19], but there is also evidence for a hypercoagulable state after partial hepatectomy $[20,21]$. Hence, the exact quantification of the positive effects of HTx is difficult to determine in this specific setting. Recently, Jorns et al. [22] demonstrated increased levels of HGF for 25 days after HTx in 2 patients with Crigler-Najjar syndrome type I who had undergone partial hepatectomy prior to HTx. The highest levels of HGF, however, were measured within the first hours after resection. Hence, both time points of HTx in our study, directly and 3 days after hepatectomy, seem feasible to improve liver function from this point of view. Although we observed a significant improvement in liver regeneration after partial hepatectomy and supportive HTx, transient functional improvement is, of course, not equivalent to a successful hepatocyte engraftment. Previous studies with similar observations reported rapid elimination of up to $70 \%$ of the transplanted cells by innate immune responses, most likely explained by the strong antigenic nature of transplanted allogeneic hepatocytes [23]. In our study, we observed a significant increase in AST levels in response to HTx (both intervention groups). Apart from the cell damage induced by the process of hepatocyte isolation and the shear stress during portal venous cell transplantation, the aforementioned immune reaction leading to further cell damage/loss may have been responsible for this phenomenon. Moreover, although the number of trans- 
planted hepatocytes varied considerably throughout comparable studies in the past, some groups transplanted considerably larger amounts of cells of up to $100 \times 10^{8}$ (vs. a mean of only about $4 \times 10^{8}$ cells in our study) [24-28]. In our study, although the adequate number of cells has not yet been defined, the transplantation of a relatively small number of hepatocytes into a relatively small FLR already led to a considerable increase in portal venous pressure and thromboembolic events of the liver and lung. Portal hypertension and postresectional hyperperfusion of the FLR are associated with increased morbidity and mortality after liver resection $[29,30]$. In our study, the portal venous pressure already increased in response to the liver resection, and even further upon HTx. The latter might be explained by the thrombotic material as a residue of cell emboli being found in portal venous branches upon histological work-up after euthanasia. Despite the absence of clinical pulmonary events in our experiments, thrombotic obliterations were also found in the pulmonary tissue, in line with a human study published by Bilir et al. [12] who observed hypoxemia and pulmonary infiltration after cell transplantation and revealed hepatocyte emboli in the lung of the recipient. In the context of transient support of liver function, to enable sufficient hepatic regeneration, repetitive HTx of smaller cell numbers could rather be performed to avoid severe clinical complications but still enable a significantly higher total number of cells to be transplanted.

Apart from the time point of transplantation and the number of cells transferred, the route of hepatocyte application offers further potential for optimizing HTx. So far, most studies refer to portal venous cell application as used in our experimental setting. Several studies of HTx via the splenic artery or into the spleen likewise reported successful hepatic cell engraftment though reducing the risk of thrombotic events as described above [31, 32]. Another recent innovative approach even completely avoided vascular injection of hepatocytes and performed HTx into the visceral lymph nodes; the development of ectopic liver tissue was observed [33].

Despite the limitation of this study regarding the lack of histological evidence for cellular engraftment, we were able to demonstrate the feasibility of HTx via the portal vein after partial hepatectomy to improve hepatic regeneration in a porcine large-animal model. Further investigations focusing on key actors in the mitogenic environment, the optimal number of cells, alternative application routes, and protocols for repetitive HTx are now required to ensure engraftment and facilitate its translation into widespread clinical application.

\section{Acknowledgement}

Parts of this work were presented in 2018 at the 22nd Surgical Research Days (Section of Surgical Research of the German Society of Surgery), in Erlangen, Germany. The authors thank Sonja Kollrich, Corinna Löbbert, and Ingrid Meder for their excellent technical support. Figure 2 was created with Biorender.com.

\section{Statement of Ethics}

This study was performed at the Laboratory for Animal Science of Hannover Medical School after approval by the Lower Saxony regional authority for consumer protection and food safety (162374). The animals were kept in housing conditions according to the EU Guideline 2010/63 and valid German Animal Regulation Act.

\section{Conflict of Interest Statement}

The authors have no conflicts of interest to declare.

\section{Funding Sources}

This study was supported by the German Research Foundation (SFB 738; FWRV, project: C11).

\section{Author Contributions}

F.O.: study conception and data acquisition, analysis, and interpretation. E.-M.W.: study conception and data acquisition and analysis. O.B.: data acquisition, analysis, and interpretation. C.A.W., L.S., H.E., P.B., and D.J.: data acquisition and analysis. M.B.: analysis and interpretation of data. K.J.: study conception and interpretation of data. F.W.R.V.: study conception and data acquisition and interpretation.

\section{References}

1 Iansante V, Mitry RR, Filippi C, Fitzpatrick E, Dhawan A. Human hepatocyte transplantation for liver disease: current status and future perspectives. Pediatr Res. 2018 Jan;83(12):232-40.

2 Mito M, Kusano M, Kawaura Y. Hepatocyte transplantation in man. Transplant Proc. 1992 Dec;24(6):3052-3.

3 Hansel MC, Gramignoli R, Skvorak KJ, Dorko $\mathrm{K}$, Marongiu F, et al. The history and use of human hepatocytes for the treatment of liver diseases: the first 100 patients. Curr Protoc Toxicol. 2014 Nov;62:14.12.1-23.

4 Schneider A, Attaran M, Meier PN, Strassburg C, Manns MP, Ott M, et al. Hepatocyte transplantation in an acute liver failure due to mushroom poisoning. Transplantation. 2006 Oct;82(8):1115-6. 
5 Forbes SJ, Gupta S, Dhawan A. Cell therapy for liver disease: from liver transplantation to cell factory. J Hepatol. 2015 Apr;62(1 Suppl):S157-69.

6 Wittauer EM, Oldhafer F, Augstein E, Beetz O, Kleine M, Schumacher C, et al. Porcine model for the study of liver regeneration enhanced by non-invasive 13C-methacetin breath test (LiMAx test) and permanent portal venous access. PLoS One. 2019 May;14(5):e0217488.

7 Oldhafer F, Wittauer EM, Beetz O, Vondran FW. Long-term Functional Maintenance of Exteriorized Portal Venous Catheters in a Porcine Animal Model. J Surg Res. 2020 Jul;251:187-94.

8 Vondran FW, Katenz E, Schwartlander R, Morgul MH, Raschzok N, Gong X, et al. Isolation of primary human hepatocytes after partial hepatectomy: criteria for identification of the most promising liver specimen. Artif Organs. 2008 Mar;32(3):205-13.

9 Kleine M, Riemer M, Krech T, DeTemple D, Jäger $\mathrm{MD}$, Lehner F, et al. Explanted diseased livers - a possible source of metabolic competent primary human hepatocytes. PLoS One. 2014 Jul;9(7):e101386.

10 Schnitzbauer AA, Bechstein WO. Technique of liver procurement in postmortem donation. Chirurg. 2013:84:380-4. German.

11 Stockmann M, Lock JF, Riecke B, Heyne K, Martus P, Fricke M, et al. Prediction of postoperative outcome after hepatectomy with a new bedside test for maximal liver function capacity. Ann Surg. 2009 Jul;250(1):119-25.

12 Bilir BM, Guinette D, Karrer F, Kumpe DA, Krysl J, Stephens J, et al. Hepatocyte transplantation in acute liver failure. Liver Transpl. 2000 Jan;6(1):32-40.

13 Gäbelein G, Nüssler AK, Morgott F, Ping Y, Nüssler N, et al. Intrasplenic or subperitoneal hepatocyte transplantation to increase survival after surgically induced hepatic failure? Eur Surg Res. 2008;41(3):253-9.

14 Nakamura Y, Mizuguchi T, Tanimizu N, Ichinohe N, Ooe H, Kawamoto M, et al. Preoperative hepatocyte transplantation improves the survival of rats with nonalcoholic steatohepatitis-related cirrhosis after partial hepatectomy. Cell Transplant. 2014;23(10):124354.
15 Park JH, Yoon YC, Hong TH, You YK, Kim DG. Effect of Liver Cell Transplantation on Acute Hepatic Failure Induced by Massive Liver Resection in the Rat. Korean J Hepatobiliary Pancreat Surg. 2011 May;15(2):10716.

16 Sigal SH, Rajvanshi P, Gorla GR, Sokhi RP, Saxena R, Gebhard DR Jr, et al. Partial hepatectomy-induced polyploidy attenuates hepatocyte replication and activates cell aging events. Am J Physiol. 1999 May;276(5):G1260-72.

17 Gramignoli R, Vosough M, Kannisto K, Srinivasan RC, Strom SC Clinical hepatocyte transplantation: practical limits and possible solutions. Eur Surg Res. 2015;54(3-4):162-77.

18 Puppi J, Strom SC, Hughes RD, Bansal S, Castell JV, Dagher I, et al. Improving the techniques for human hepatocyte transplantation: report from a consensus meeting in London. Cell Transplant. 2012;21(1):1-10.

19 Dhawan A, Mitry RR, Hughes RD, Lehec S, Terry C, Bansal S, et al. Hepatocyte transplantation for inherited factor VII deficiency. Transplantation. 2004 Dec;78(12):1812-4.

20 Cerutti E, Stratta C, Romagnoli R, Schellino MM, Skurzak S, Rizzetto M, et al. Thromboelastogram monitoring in the perioperative period of hepatectomy for adult living liver donation. Liver Transpl. 2004 Feb;10(2):28994.

21 Barton JS, Riha GM, Differding JA, Underwood SJ, Curren JL, Sheppard BC, et al. Coagulopathy after a liver resection: is it overdiagnosed and over-treated? HPB (Oxford). 2013 Nov; 15(11):865-71

22 Jorns C, Nowak G, Nemeth A, Zemack H, Mörk LM, Johansson H, et al. De Novo DonorSpecific HLA Antibody Formation in Two Patients with Crigler-Najjar Syndrome Type I following Human Hepatocyte Transplantation with Partial Hepatectomy Preconditioning. Am J Transplant. 2016 Mar;16(3):1021-30.

23 Gupta S, Rajvanshi P, Sokhi R, Slehria S, Yam A, Kerr A, et al. Entry and integration of transplanted hepatocytes in rat liver plates occur by disruption of hepatic sinusoidal endothelium. Hepatology. 1999 Feb;29(2):509-19.

24 Maruyama M, Totsugawa T, Kunieda T, Okitsu T, Shibata N, Takesue M, et al. Hepatocyte isolation and transplantation in the pig. Cell Transplant. 2003;12(6):593-8.
25 Arkadopoulos N, Chen SC, Khalili TM, Detry $\mathrm{O}$, Hewitt WR, Lilja H, et al. Transplantation of hepatocytes for prevention of intracranial hypertension in pigs with ischemic liver failure.CellTransplant.1998Jul-Aug;7(4):357-63.

26 Rosenthal RJ, Chen SC, Hewitt W, Wang CC Eguchi S, Geller S, et al. Techniques for intrasplenic hepatocyte transplantation in the large animal model. Surg Endosc. 1996 Nov;10(11):1075-9.

27 Muraca M, Neri D, Parenti A, Feltracco P, Granato A, Vilei MT, et al. Intraportal hepatocyte transplantation in the pig: hemodynamic and histopathological study. Transplantation. 2002 Mar;73(6):890-6.

28 Kobayashi E, Enosawa S, Nagashima H. Experimental Hepatocyte Transplantation in Pigs. Methods Mol Biol. 2017;1506:149-60.

29 Bogner A, Reissfelder C, Striebel F, Mehrabi A, Ghamarnejad O, Rahbari M, et al. Intraoperative Increase of Portal Venous Pressure Is an Immediate Predictor of Posthepatectomy Liver Failure after Major Hepatectomy: A Prospective Study. Ann Surg. 2019. Online ahead of print.

30 Allard MA, Adam R, Bucur PO, Termos S, Cunha AS, Bismuth $\mathrm{H}$, et al. Posthepatectomy portal vein pressure predicts liver failure and mortality after major liver resection on noncirrhotic liver. Ann Surg. 2013 Nov;258(5):822-9.

31 Raschzok N, Teichgräber U, Billecke N, Zielinski A, Steinz K, Kammer NN, et al. Monitoring of Liver Cell Transplantation in a Preclinical Swine Model Using Magnetic Resonance Imaging. Cell Med. 2010 Dec;1(3):123-35.

32 Siefert J, Hillebrandt KH, Moosburner S, Podrabsky P, Geisel D, Denecke T, et al. Hepatocyte Transplantation to the Liver via the Splenic Artery in a Juvenile Large Animal Model. Cell Transplant. 2019 Dec;28 1 suppl:14S-24S.

33 Fontes P, Komori J, Lopez R, Marsh W, Lagasse E. Development of Ectopic Livers by Hepatocyte Transplantation into Swine Lymph Nodes. Liver Transpl. 2020 Dec;26(12):162943. 